N Engl J Med. 2005 April 21; 352(16): 1677-1684. doi:10.1056/NEJMcp043511.

\title{
Rehabilitation after Stroke
}

\author{
Bruce H. Dobkin, M.D. \\ Department of Neurology, the Neurologic Rehabilitation and Research Program, Geffen School of \\ Medicine, University of California at Los Angeles, Los Angeles
}

\begin{abstract}
A 66-year-old man was suddenly unable to speak, follow directions, or move his right arm and leg. He received tissue plasminogen activator within 90 minutes. Four days later, his speech was limited to effortful answers of yes or no. He could not walk or use his right arm, and self-care tasks required maximal assistance. What advice would you offer him and his family regarding rehabilitation for his disabilities?
\end{abstract}

\section{THE CLINICAL PROBLEM}

Approximately 400 persons per 100,000 population over the age of 45 years have a first stroke each year in the United States, Europe, and Australia. Stroke is the most frequent cause of adult-onset disability among people in the United States, and the cost of related care is among the fastest-growing expenses for Medicare. ${ }^{1}$

The likelihood of improvement after stroke varies with the nature and severity of the initial deficit. Approximately 35 percent of survivors with initial paralysis of the leg do not regain useful function, and 20 to 25 percent of all survivors are unable to walk without full physical assistance. ${ }^{2}$ Six months after stroke, about 65 percent of patients cannot incorporate the affected hand into their usual activities. Poor upper-extremity outcomes are probable after a hemispheric infarction when the leg cannot move by two weeks and the hand has no movement or only slight finger flexion with no opening by four weeks, consistent with considerable damage to the corticospinal tract. ${ }^{3}$

Patients who survive a stroke almost always have less physical disability by the end of the first three months. Functional scales, such as the Barthel Index and the Functional Independence Measure (which measure the physical assistance or supervision needed for self-care, including using the toilet, dressing, bathing, eating, and mobility), tend to show a plateau of gains by three to four months after stroke, partly owing to insensitivity of the scale to further improvements. Patients who no longer require assistance at that point may still be unable to use the affected hand, walk at speeds and distances that permit activities outside the home, or live alone. Only 25 percent of patients return to the level of everyday participation and physical functioning of community-matched persons who have not had a

Copyright $(2005$ Massachusetts Medical Society.

Address reprint requests to Dr. Dobkin at the Department of Neurology, the Neurologic Rehabilitation and Research Program, Geffen School of Medicine, University of California at Los Angeles, 710 Westwood Plaza, Los Angeles, CA 90095, or at bdobkin@ mednet.ucla.edu. 
stroke. ${ }^{4}$ The quality of life tends to be higher among patients with better functioning than among those with worse functioning. ${ }^{5}$

Improvement especially during the first few weeks after a stroke reflects the recovery of neurotransmission in spared tissue near and remote from an infarct or hemorrhage. ${ }^{6,7}$ At any time after the stroke, however, cognitive, language, and motor skills may improve by means of the cerebral processes involved in ordinary learning. This experience-induced neuroplasticity includes greater excitability and recruitment of the neurons in both hemispheres of the brain that contribute to performance, sprouting of dendrites that communicate with other neurons, and strengthening of these synaptic connections. Functional neuroimaging studies have shown the evolution of cerebral activity within both hemispheres as patients' skills improve with training and experience. ${ }^{8}$

\section{STRATEGIES AND EVIDENCE}

Neurorehabilitation studies of patients who have had a stroke often have limitations, including heterogeneity of impairments and disabilities, poorly defined or controlled interventions, small differences in treatment time or type of treatment, lack of randomization or masking, inadequate samples, and insensitive outcome measures. ${ }^{9}$ In well-designed rehabilitation trials, the magnitude of improvement with the guidance of physical or occupational therapy tends to be modest but clinically useful, such as a 5-point increase in the Barthel Index (with a range of 0 to 15 , with higher numbers indicating greater independence) or an increase in walking speed of $0.10 \mathrm{~m}$ per second. ${ }^{10}$ This article focuses on sound randomized trials and metaanalyses of rehabilitation strategies that are useful after hemiplegic stroke.

\section{SETTINGS FOR THERAPY}

Inpatient rehabilitation is recommended for patients who are too disabled to return home but who have adequate cognition and fitness to participate in therapy for three hours a day, who need ongoing supervision by nurses and physicians for medical care and education, and who have sufficient social support to return home (Fig. 1). ${ }^{11}$ The most common disability that leads to referral to inpatient rehabilitation is the inability to walk safely without physical help. On the basis of Medicare coverage policies, the current median length of stay in an inpatient rehabilitation facility is only 16 days, so efficient services are essential. ${ }^{12}$ Approximately 80 percent of patients who undergo inpatient rehabilitation are discharged to their homes. Medicare pays for home-based rehabilitation services for the next few weeks after discharge, when patients are too disabled to travel, and then for treatment two to three times a week at an outpatient facility for a period of one to three months, until the patient reaches a plateau in terms of gains in activities of daily living.

The results of a meta-analysis indicate that care in an inpatient stroke unit that provides multidisciplinary services, coordinates disability-related medical care, and trains caregivers results in fewer deaths, less disability, and less need for institutionalization in nursing facilities, as compared with hospital care on general wards. ${ }^{13}$ Such care may enable an extra 5 patients of every 100 to return home. ${ }^{14}$ 
Randomized trials that compare inpatient rehabilitation with community-based care designed to permit earlier hospital discharge of patients who need only intermittent assistance generally find that caregivers have greater stress when these patients are discharged early, but that the functional outcomes among these patients are equal to those of patients receiving inpatient rehabilitation. ${ }^{15}$ Just four hours of rehabilitation training of motivated caregivers may improve their mood and quality of life and reduce short-term financial costs. ${ }^{16}$ Small trials support the benefit of training caregivers specifically to assist patients in safe swallowing, speech, and walking for exercise and in finding solutions for managing daily activities. Therapists can monitor and advance this home training.

Coordinated direction of outpatient therapies, assistance in finding community resources such as transportation and support groups, and counseling about sexuality, nutrition, and exercise have been shown to improve the patients' skills in activities of daily living and participation in the community, as compared with patients who do not receive such coordinated services. ${ }^{17}$

\section{TARGETED THERAPY}

Aphasia-About 20 percent of patients have impaired expression and comprehension of language after a stroke and should receive speech therapy. The broad range of the types and severity of aphasia, as well as the diverse strategies used in its treatment, complicates the design of clinical trials. A meta-analysis of the diverse approaches used to treat all patients with aphasia after stroke showed a positive, moderate effect for treatment begun within the first 3 months after stroke, as compared with no treatment, as well as a smaller but positive effect when treatment was initiated between 3 to 12 months after stroke and even after more than 1 year. ${ }^{18}$ The results of trials may not reflect the small gains that benefit the patient and family, such as greater accuracy of yes and no responses, gestures or pointing to pictures to indicate needs, and suppression of repetitive babble. Patients treated by speech therapists perform better than those treated by trained volunteers. ${ }^{19}$ Greater intensity of treatment, ranging from 40 to 100 hours ( 5 hours or more weekly) of treatment targeted to specific impairments, correlates directly with the magnitude of improvement, primarily among patients whose stroke occurred less than six months previously. ${ }^{20-22}$ Improvements in targeted language impairments have been associated with changes in activity in the cortical regions of the brain associated with language skills. ${ }^{23,24}$

Self-Care and Functional Use of the Arm-Significant benefit is most often achieved among patients with moderate levels of disability as measured on functional scales, but not among those with the greatest disability. ${ }^{25}$ For patients with hemiplegia, the initial functional training emphasizes compensatory strategies. For example, patients learn to transfer from a bed into a wheelchair for mobility, and self-care is performed with onehanded techniques with the use of the unaffected arm. Overnight splinting maintains wrist and finger extension but may not improve the range of motion in the affected hand or reduce pain. ${ }^{26}$ Recent trials emphasize the practice of task-related movements (Table 1). Many different task-oriented practice strategies have shown significantly greater benefit from more intensive therapies (16 or more additional hours of treatment) that involve training in specific skills, ${ }^{10,27}$ as compared with only several additional hours a week of general rehabilitation spread among many activities. ${ }^{28}$ 
Initial interventions for the affected arm are aimed at eliciting small voluntary or reflexive involuntary movements. Training the arm for functional activities can start when the arm and hand begin to overcome gravity. If no hand dexterity is apparent by six weeks after stroke, ${ }^{3}$ further rehabilitation should emphasize maintaining a comfortably mobile arm.

Protocols for constraint-induced-movement therapy are based on the theory that nonuse of an arm may result from the great effort required to perform tasks with the affected hand. ${ }^{29}$ This therapeutic approach emphasizes intensive task-specific practice with the affected hand, for three to six hours a day over a period of from two to six weeks. As in other taskoriented interventions, the therapy progresses by gradual approximations from minimal movements to fuller actions of reaching for and grasping and pinching items that a patient would ordinarily use (Table 1). Some protocols re-strain the unaffected hand to force greater use of the affected hand. The key requirement, and the primary limitation, of this approach is that patients must have at least 10 degrees of finger and wrist extension, which equates to rather good motor control, in order to benefit from the therapy. As a result, perhaps only 10 percent of patients may benefit from this strategy. ${ }^{30}$ Clinical trials indicate that patients who practice at this intensity increase the amount and efficiency of use of the affected hand by 20 to 50 percent, whether therapy is begun while they are inpatients or a year after the stroke. ${ }^{31,32}$

Many technology-assisted approaches to improve the functional use of a hand have been tried. In small trials, electromyographic biofeedback, which is used to help patients focus on increasing the force of contraction necessary to move a paretic wrist or to improve pinching and grasping, has increased movement but has less often improved the functional use of the hand. ${ }^{33,34}$ Larger randomized trials of the use of acupuncture to improve functional use of the hand have shown little or no benefit when sham puncture (i.e., insertion of the needle outside a traditional zone or without stimulation) served as a control. ${ }^{35}$

Spasticity is often blamed for poor hand function in patients with minimal wrist and finger extension but some preservation of flexion. Contracture and change in the morphologic features of muscle ${ }^{36}$ contribute to a flexed posture, but poor motor control with weakness, not hypertonia, is the primary cause of disability ${ }^{37}$ In a randomized trial, the injection of botulinum toxin into the muscles of the arm reduced excessive flexion and the associated pain, spasms, or postures that interfered with patients' self-care, ${ }^{38}$ but the induced muscle weakness usually does not improve the functional use of the hand. The injection must be followed by stretching exercises and treatment of pain that may exacerbate the hypertonicity.

Walking-Independent walking is a primary goal and a reasonable expectation for most patients. Inpatients who develop at least partial movement against gravity for hip flexion and knee extension will progress from single steps taken between parallel bars to at least slow walking for short distances with the use of a walker or cane and hands-on assistance from another person for balance. A molded plastic orthosis for the ankle and foot may stabilize a weak ankle and knee to improve foot clearance and prevent the knee from buckling ${ }^{39}$ without impeding the subsequent recovery of dorsiflexion in the ankle. The recovery of the ability to walk even short distances requires considerable practice. Even in a dedicated 
rehabilitation unit, however, patients may spend little more than 15 minutes a day engaged in mobility tasks. ${ }^{40}$

Randomized trials show that patients who walk slowly (i.e., less than $0.4 \mathrm{~m}$ per second) can improve their speed and endurance significantly even when treatment begins from 3 months to more than 12 months after a stroke. Successful interventions involve one or more cycles of from 12 to 20 hours of task-oriented exercise over a period of four weeks, such as practicing walking outdoors or on a treadmill or obstacle course and exercising to improve leg strength and balance. ${ }^{10,25}$ Training on a treadmill with the use of partial body-weight support (the attachment of an overhead lift to a harness on the patient's chest) allows patients to take more steps at faster speeds than may otherwise be feasible. Randomized trials initiated during inpatient rehabilitation, however, have shown clinically insignificant increases in speed and distance of walking, as compared with conventional training. More data are needed to make it possible to assess whether this approach can improve walking among patients who persistently walk poorly at three to six months after a stroke, when gains have reached an apparent plateau after conventional therapy. ${ }^{41}$

Exercise and Strengthening-In patients with hemiparesis, the rates of production of muscle force, power, speed of sequential movements, and resistance to fatigue are impaired. Although neural factors that affect motor control account for much of the impairment, changes in muscle fibers and atrophy induced by inactivity may contribute. In randomized trials, progressive resistance exercises performed three to four times weekly for a period of from 6 to 12 weeks by patients with adequate motor control improved strength and functional activities. ${ }^{42}$ Fitness often declines in disabled persons, but trials show gains with progressive aerobic exercises, such as walking on a treadmill three days a week, that are tailored to each patient's tolerance, even when the exercise is initiated years after a stroke. ${ }^{43}$

\section{OTHER FACTORS AFFECTING REHABILITATION}

Attention to modifiable conditions that may interfere with the effectiveness of efforts toward rehabilitation is routinely warranted. For example, pre-existing conditions such as painful osteoarthritis or cardiopulmonary disease may limit exercise tolerance. Other modifiable factors that limit participation in exercise include sleep disorders, pain, adverse effects of medications (such as orthostatic hypotension and impaired concentration), mood disorders, and incontinence or urinary retention. Depression is especially prevalent, affecting 25 to 40 percent of patients within the first year after a stroke. ${ }^{44}$ Randomized, placebo-controlled trials of citalopram, fluoxetine, methylphenidate, and nortriptyline suggest that mid-range doses of these medications (e.g., a dose of 50 to $100 \mathrm{mg}$ when a low dose is $<50 \mathrm{mg}$ and a high dose is $>100 \mathrm{mg}$ ) increase patients' participation in rehabilitation activities ${ }^{45}$ and may lessen cognitive deficits in some depressed patients. ${ }^{46}$ Other issues that are not medical, such as the costs of a caregiver and of remodeling the home to eliminate physical barriers, also affect patients' efforts and goals for rehabilitation.

\section{AREAS OF UNCERTAINTY}

Formal therapy is often stopped when patients show no qualitative gains after a few weeks of treatment. A plateau in recovery, however, does not necessarily imply a diminished 
capacity for further gains in physical speed or precision or in learning a new task. At present, the opportunity to achieve maximal improvement is probably constrained by a lack of adequate data to define the optimal intensity (performance time, pace, and duration) of training strategies for specific disabilities. Functional neuroimaging studies may, in the future, help to guide decisions about the type and duration of treatment by providing insight into the maximal cortical reorganization that can be achieved with a particular therapy over time ${ }^{47,48}$; however, this possibility requires much more research.

Several potential interventions need further study. Small trials have shown modest clinical improvement in disabilities after stroke with the use of the following techniques: electrical stimulation over the surface of muscles to contract them for simple movements, such as grasping, or to assist ankle dorsiflexion while walking ${ }^{49}$; intense practice with electromechanical devices that assist in reaching or stepping ${ }^{50}$; noninvasive stimulation of the peripheral nerve of the $\operatorname{arm}^{51}$ or direct stimulation of the motor cortex over the hand representation ${ }^{52}$ to augment cortical plasticity and learning during arm therapies; pharmacotherapy with agonists of dopamine, acetylcholine, and serotonin, which may modulate neurotransmission and learning ${ }^{53}$; and the use of mental imagery of an action, ${ }^{54}$ which may enhance training because it activates many of the same cortical neurons that are involved in performing the action. Phase 1 trials are beginning in order to assess the safety of the injection of drugs into the cerebrospinal fluid or of cells into brain tissue to replace neurons and promote dendrite sprouting and axon regeneration, ${ }^{55}$ with the goal of possible neural repair.

\section{GUIDELINES}

Guidelines of the American Heart Association ${ }^{56}$ and the Royal College of Physicians ${ }^{57}$ recommend the long-term use of aerobic training; exercises to enhance flexibility, balance, and coordination; and resistance exercises within daily activities for patients after a stroke.

\section{SUMMARY AND CONCLUSIONS}

Patients who have substantial neurologic impairments after a stroke and are expected to be able to return home, such as the one described in the vignette, are likely to benefit from inpatient rehabilitation. By the time of discharge, the patient should be able to provide reliable yes and no responses to questions and express himself or herself in short phrases, use the unaffected hand much more effectively for self-care, and walk $50 \mathrm{~m}$ slowly with handson supervision, aided by a cane and ankle-foot orthosis; he or she would be expected to need some physical help for self-care. Physical, occupational, and speech therapy after discharge should be focused on training in tasks needed to increase independence for activities at home and in the community. Successful learning of a personal skill may require 20 or more hours of practice. Formal training of caregivers should be encouraged. Treatable conditions such as depression should be identified. Ongoing improvement in movement and language skills is possible with further practice (Table 1) at any time after stroke, consistent with the plasticity of intact neural pathways. 


\section{Acknowledgments}

Supported by grants (HD39629, HD046740, and HD07479) from the National Institutes of Health and by the Larry L. Hillblom Foundation.

\section{REFERENCES}

1. Centers for Disease Control. Hospitalizations for stroke among adults aged over 65 years - United States, 2000. JAMA. 2003; 290:1023-1024.

2. Hendricks HT, van Limbeek J, Geurts AC, Zwarts MJ. Motor recovery after stroke: a systematic review. Arch Phys Med Rehabil. 2002; 83:1629-1637. [PubMed: 12422337]

3. Kwakkel G, Kollen BJ, van der Grond J, Prevo AJ. Probability of regaining dexterity in the flaccid upper limb: impact of severity of paresis and time since onset in acute stroke. Stroke. 2003; 34:2181-2186. [PubMed: 12907818]

4. Lai S-M, Studenski S, Duncan PW, Perera S. Persisting consequences of stroke measured by the Stroke Impact Scale. Stroke. 2002; 33:1840-1844. [PubMed: 12105363]

5. Samsa GP, Matchar DB. How strong is the relationship between functional status and quality of life among persons with stroke? J Rehabil Res Dev. 2004; 41:279-282. [PubMed: 15543445]

6. Binkofski F, Seitz RJ. Modulation of the BOLD-response in early recovery from sensorimotor stroke. Neurology. 2004; 63:1223-1229. [PubMed: 15477542]

7. Carmichael ST, Tatsukawa K, Katsman D, Tsuyuguchi N, Kornblum HI. Evolution of diaschisis in a focal stroke model. Stroke. 2004; 35:758-763. [PubMed: 14963280]

8. Baron J-C, Cohen LG, Cramer SC, et al. Neuroimaging in stroke recovery: a position paper from the First International Workshop on Neuroimaging and Stroke Recovery. Cerebrovasc Dis. 2004; 18:260-267. [PubMed: 15484327]

9. Dobkin, BH. The clinical science of neurologic rehabilitation. New York: Oxford University Press; 2003.

10. Kwakkel G, van Peppen R, Wagenaar RC, et al. Effects of augmented exercise therapy time after stroke: a meta-analysis. Stroke. 2004; 35:2529-2539. [PubMed: 15472114]

11. Gresham, GE.; Duncan, PW.; Stason, WB., et al. Clinical practice guideline 16. Hyattsville, Md.: Public Health Service; 1995. Post-stroke rehabilitation: assessment, referral, and patient management. (DHHS publication no. (AHCPR) 95-0663.)

12. Ottenbacher KJ, Smith PM, Illig SB, Linn RT, Ostir GV, Granger CV. Trends in length of stay, living setting, functional outcome, and mortality following medical rehabilitation. JAMA. 2004; 292:1687-1695. [PubMed: 15479933]

13. Organized inpatient (stroke unit) care after stroke. Cochrane Database Syst Rev. 2000; 2:CD000197. [PubMed: 10796318]

14. Langhorne P, Duncan P. Does the organization of postacute stroke care really matter? Stroke. 2001; 32:268-274. [PubMed: 11136947]

15. Donnelly M, Power M, Russell M, Fullerton K. Randomized controlled trial of an early discharge rehabilitation service: the Belfast Community Stroke Trial. Stroke. 2004; 35:127-133. [PubMed: 14671238]

16. Kalra L, Evans A, Perez I, et al. Training carers of stroke patients: randomised controlled trial. BMJ. 2004; 328:1099-1104. [PubMed: 15130977]

17. Legg L, Langhorne P. Rehabilitation therapy services for stroke patients living at home: systematic review of randomised trials. Lancet. 2004; 363:352-356. [PubMed: 15070563]

18. Robey RR. A meta-analysis of clinical outcomes in the treatment of aphasia. J Speech Lang Hear Res. 1998; 41:172-187. [PubMed: 9493743]

19. Greener J, Enderby P, Whurr R. Speech and language therapy for aphasia following stroke. Cochrane Database Syst Rev. 2000; 2:CD000425. [PubMed: 10796360]

20. Bhogal SK, Teasell R, Speechley M. Intensity of aphasia therapy, impact on recovery. Stroke. 2003; 34:987-993. [PubMed: 12649521] 
21. Doesborgh SJ, van de Sandt-Koenderman MW, Dippel DW, van Harskamp F, Koudstaal PJ, Visch-Brink EG. Effects of semantic treatment on verbal communication and linguistic processing in aphasia after stroke: a randomized controlled trial. Stroke. 2004; 35:141-146. [PubMed: 14657447]

22. Pulvermuller F, Neininger B, Elbert T, et al. Constraint-induced therapy of chronic aphasia after stroke. Stroke. 2001; 32:1621-1626. [PubMed: 11441210]

23. Musso M, Weiller C, Kiebel S, Muller SP, Bulau P, Rijntjes M. Training-induced brain plasticity in aphasia. Brain. 1999; 122:1781-1790. [PubMed: 10468516]

24. Peck KK, Moore AB, Crosson BA, et al. Functional magnetic resonance imaging before and after aphasia therapy: shifts in hemodynamic time to peak during an overt language task. Stroke. 2004; 35:554-559. [PubMed: 14739418]

25. Dobkin BH. Strategies for stroke rehabilitation. Lancet Neurol. 2004; 3:528-536. [PubMed: 15324721]

26. Lannin NA, Horsley SA, Herbert R, McCluskey A, Cusick A. Splinting the hand in the functional position after brain impairment: a randomized, controlled trial. Arch Phys Med Rehabil. 2003; 84:297-302. [PubMed: 12601664]

27. Steultjens EM, Dekker J, Bouter LM, van de Nes JC, Cup EH, van den Ende CH. Occupational therapy for stroke patients: a systematic review. Stroke. 2003; 34:676-687. [PubMed: 12624291]

28. Lincoln NB, Parry RH, Vass CD. Randomized, controlled trial to evaluate increased intensity of physiotherapy treatment of arm function after stroke. Stroke. 1999; 30:573-579. [PubMed: 10066854]

29. Wolf SL, Blanton S, Baer H, Breshears J, Butler AJ. Repetitive task practice: a critical review of constraint-induced movement therapy in stroke. Neurologist. 2002; 8:325-338. [PubMed: 12801434]

30. Grotta JC, Noser EA, Ro T, et al. Constraint-induced movement therapy. Stroke. 2004; 35(Suppl 1):2699-2701. [PubMed: 15375308]

31. Dromerick AW, Edwards DF, Hahn M. Does the application of constraint-induced movement therapy during acute rehabilitation reduce arm impairment after ischemic stroke? Stroke. 2000; 31:2984-2988. [PubMed: 11108760]

32. van der Lee J. Constraint-induced therapy for stroke: more of the same or something completely different? Curr Opin Neurol. 2001; 14:741-744. [PubMed: 11723382]

33. Barreca S, Wolf SL, Fasoli S, Bohannon R. Treatment interventions for the paretic upper limb of stroke survivors: a critical review. Neurorehabil Neural Repair. 2003; 17:220-226. [PubMed: 14677218]

34. Bolton DA, Cauraugh JH, Hausenblas HA. Electromyogram-triggered neuromuscular stimulation and stroke motor recovery of arm/hand functions: a meta-analysis. J Neurol Sci. 2004; 223:121127. [PubMed: 15337612]

35. Johansson BB, Haker E, von Arbin M, et al. Acupuncture and transcutaneous nerve stimulation in stroke rehabilitation: a randomized, controlled trial. Stroke. 2001; 32:707-713. [PubMed: 11239191]

36. Lieber RL, Runesson E, Einarsson F, Friden J. Inferior mechanical properties of spastic muscle bundles due to hypertrophic but compromised extracellular matrix material. Muscle Nerve. 2003; 28:464-471. [PubMed: 14506719]

37. Sommerfeld DK, Eek EU, Svensson A-K, Holmqvist LW, von Arbin MH. Spasticity after stroke: its occurrence and association with motor impairments and activity limitations. Stroke. 2004; 35:134-139. [PubMed: 14684785]

38. Brashear A, Gordon MF, Elovic E, et al. Intramuscular injection of botulinum toxin for the treatment of wrist and finger spasticity after a stroke. N Engl J Med. 2002; 347:395-400. [PubMed: 12167681]

39. de Wilt DC, Buurke JH, Nijlant JM, Ijzerman MJ, Hermens HJ. The effect of an ankle-foot orthosis on walking ability in chronic stroke patients: a randomized controlled trial. Clin Rehabil. 2004; 18:550-557. [PubMed: 15293489] 
40. Glasgow Augmented Physiotherapy Study Group. Can augmented physiotherrapy input enhance recovery of mobility after stroke? A randomized controlled trial. Clin Rehabil. 2004; 18:529-537. [PubMed: 15293487]

41. Moseley AM, Stark A, Cameron ID, Pollock A. Treadmill training and body weight support for walking after stroke. Stroke. 2003; 34:3006. [PubMed: 14615617]

42. Patten C, Lexell J, Brown HE. Weakness and strength training in persons with post-stroke hemiplegia: rationale, method, and efficacy. J Rehabil Res Dev. 2004; 41:293-312. [PubMed: 15543447]

43. Saunders DH, Greig CA, Young A, Mead GE. Physical fitness training for stroke patients. Cochrane Database Syst Rev. 2004; 1:CD003316. [PubMed: 14974012]

44. Eriksson M, Asplund K, Glader EL, et al. Self-reported depression and use of anti-depressants after stroke: a national survey. Stroke. 2004; 35:936-941. [PubMed: 15001790]

45. Van de Meent H, Geurts AC, Van Limbeek J. Pharmacologic treatment of post-stroke depression: a systematic review of the literature. Top Stroke Rehabil. 2003; 10:79-92. [PubMed: 12970833]

46. Narushima K, Chan KL, Kosier JT, Robinson RG. Does cognitive recovery after treatment of poststroke depression last? A 2-year follow-up of cognitive function associated with poststroke depression. Am J Psychiatry. 2003; 160:1157-1162. [PubMed: 12777275]

47. Dobkin BH, Firestine A, West M, Saremi K, Woods R. Ankle dorsiflexion as an fMRI paradigm to assay motor control for walking during rehabilitation. Neuroimage. 2004; 23:370-381. [PubMed: 15325385]

48. Koski L, Mernar TJ, Dobkin BH. Immediate and long-term changes in corticomotor output response to rehabilitation: correlation with functional improvements in chronic stroke. Neurorehabil Neural Repair. 2004; 18:230-249. [PubMed: 15537994]

49. Yan T, Hui-Chan CW, Li LS. Functional electrical stimulation improves motor recovery of the lower extremity and walking ability of subjects with first acute stroke: a randomized placebocontrolled trial. Stroke. 2005; 36:80-85. [PubMed: 15569875]

50. Hesse S, Schmidt H, Werner C, Bardeleben A. Upper and lower extremity robotic devices for rehabilitation and for studying motor control. Curr Opin Neurol. 2003; 16:705-710. [PubMed: 14624080]

51. Dobkin BH. Do electrically stimulated sensory inputs and movements lead to long-term plasticity and rehabilitation gains? Curr Opin Neurol. 2003; 16:685-692. [PubMed: 14624077]

52. Hummel F, Celnik P, Giraux P, et al. Effects of non-invasive cortical stimulation on skilled motor function in chronic stroke. Brain. 2005; 128:490-499. [PubMed: 15634731]

53. Plewnia C, Hoppe J, Cohen LG, Gerloff C. Improved motor skill acquisition after selective stimulation of central norepinephrine. Neurology. 2004; 62:2124-2126. [PubMed: 15184632]

54. Liu KP, Chan CC, Lee TM, Hui-Chan CW. Mental imagery for promoting relearning for people after stroke: a randomized controlled trial. Arch Phys Med Rehabil. 2004; 85:1403-1408. [PubMed: 15375808]

55. Kondziolka D, Wechsler L, Achim C. Neural transplantation for stroke. J Clin Neurosci. 2002; 9:225-230. [PubMed: 12093124]

56. Gordon NF, Gulanick M, Costa F, et al. Physical activity and exercise recommendations for stroke survivors. Circulation. 2004; 109:2031-2041. [PubMed: 15117863]

57. Wade, DT. Intercollegiate Working Party for Stroke. National clinical guidelines for stroke. London: Royal College of Physicians; 2002. 


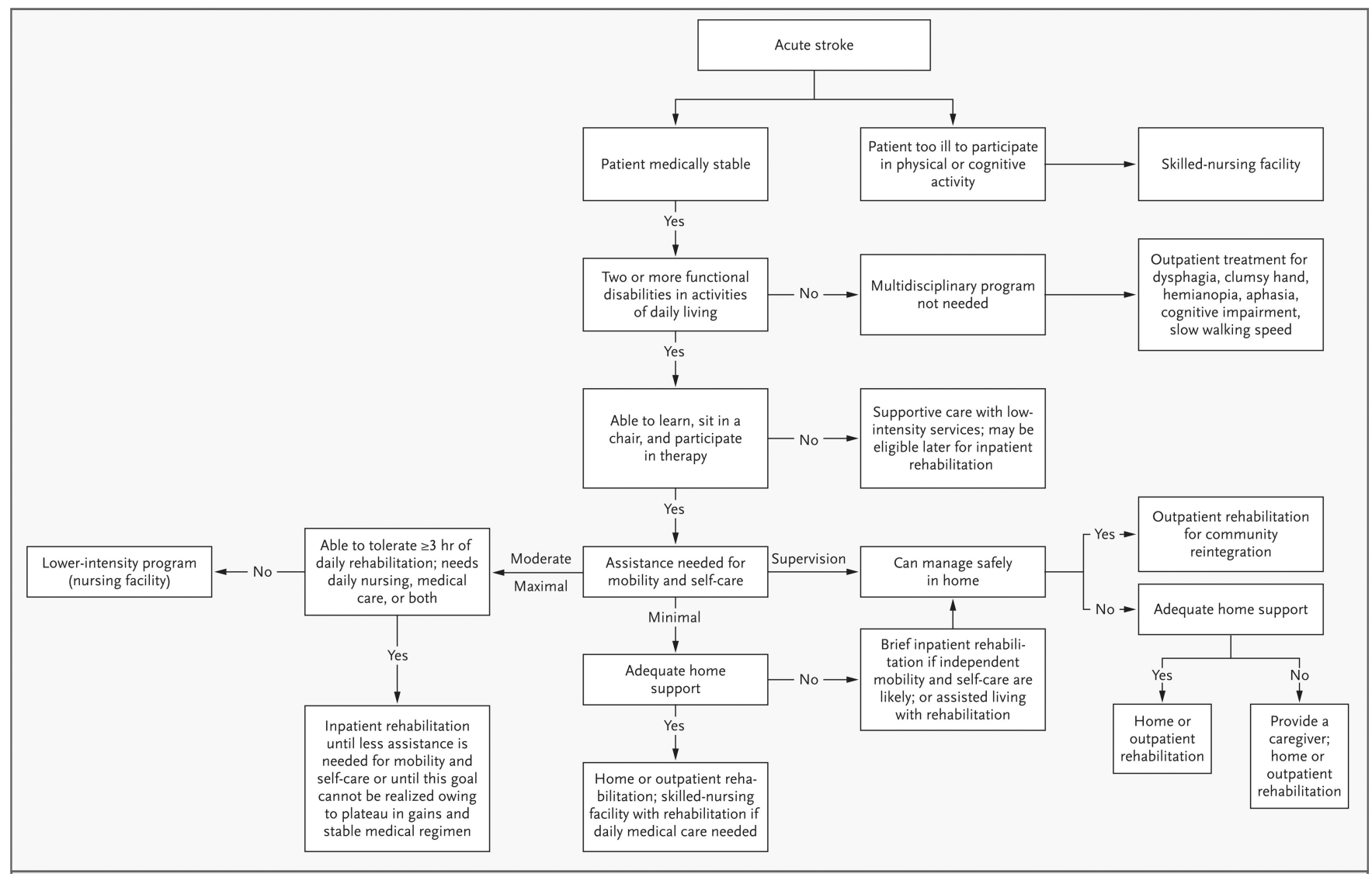

Figure 1. Algorithm for Placement for Rehabilitation Care after Stroke

Minimal assistance denotes physical help from another person that consists of no more than touching while the patient expends 75 percent of the effort (e.g., to walk, reach for an object, manage self-care); moderate assistance denotes physical help needed while the patient expends 50 to 75 percent of the effort; and maximal assistance denotes physical help needed while the patient expends less than 50 percent of the effort. 


\section{Table 1}

\section{Strategies for Therapy That Clinicians Can Encourage after Hemiplegic Stroke.}

\begin{tabular}{|c|c|c|}
\hline Time and Setting & Focus & Example of Target \\
\hline $\begin{array}{l}\text { Week 1, acute } \\
\text { hospitalization }\end{array}$ & Assessment & $\begin{array}{l}\text { Assess ability to swallow and amount of assistance patient needs for activities of } \\
\text { daily living }\end{array}$ \\
\hline \multirow{4}{*}{$\begin{array}{l}\text { Weeks } 2 \text { to } 6 \text {, } \\
\text { inpatient } \\
\text { rehabilitation }\end{array}$} & Assessment & $\begin{array}{l}\text { Specify impairments, disabilities, and household barriers that are the goals of } \\
\text { intervention }\end{array}$ \\
\hline & $\begin{array}{l}\text { Training in compensatory } \\
\text { techniques }\end{array}$ & $\begin{array}{l}\text { Train in one-handed dressing, bathing, using the toilet; if liquids (but not thicker } \\
\text { substances) are aspirated during a modified barium swallow, use puréed foods } \\
\text { and liquids the consistency of honey and instruct patient to rotate and flex the } \\
\text { head to the weak side with each swallow and to double swallow (i.e., swallow } \\
\text { food or liquid, then swallow again, to clear throat) }\end{array}$ \\
\hline & $\begin{array}{l}\text { Practicing components of } \\
\text { impaired movement of affected } \\
\text { limbs to achieve increasingly } \\
\text { complex and task-specific } \\
\text { actions }\end{array}$ & $\begin{array}{l}\text { Have patient practice reaching for small items with the affected arm within the } \\
\text { work space between the shoulder and lap, with the use of elbow support if } \\
\text { needed, and opening the affected hand to match the diameter of an object, then } \\
\text { grasping or pinching the object and releasing it }\end{array}$ \\
\hline & $\begin{array}{l}\text { Training that requires attention } \\
\text { and is progressively more } \\
\text { demanding, oriented toward } \\
\text { tasks relevant to the patient, and } \\
\text { rewarded with feedback }\end{array}$ & $\begin{array}{l}\text { Monitor distance walked or time needed to walk } 10 \mathrm{~m} \text {; choose a self-care task } \\
\text { and give feedback on the quality of movement and problem-solving during } \\
\text { practice }\end{array}$ \\
\hline \multirow[t]{5}{*}{$\begin{array}{l}\text { Months } 1 \text { to } 6 \text {, } \\
\text { outpatient } \\
\text { rehabilitation }\end{array}$} & $\begin{array}{l}\text { Use of simple but relevant test- } \\
\text { retest measures over the course } \\
\text { of therapy to help monitor } \\
\text { success or the need to try another } \\
\text { approach }\end{array}$ & $\begin{array}{l}\text { Serially record the distance walked in } 5 \text { min or time needed to loop shirt buttons; } \\
\text { if patient has dysnomia, monitor the percentage of correctly named items; record } \\
\text { the percentage of items found in the left half of a room as patient compensates for } \\
\text { a left visual hemineglect }\end{array}$ \\
\hline & $\begin{array}{l}\text { Practice that is progressive in } \\
\text { intensity and at levels of } \\
\text { difficulty near maximal } \\
\text { performance }\end{array}$ & $\begin{array}{l}\text { Focus on the accuracy, precision, rate, and duration of performing each task; aim } \\
\text { to increase walking speed to }>0.75 \mathrm{~m} \text { per sec for unlimited walking in the } \\
\text { community }\end{array}$ \\
\hline & $\begin{array}{l}\text { Repetitive practice that varies } \\
\text { tasks and their requirements }\end{array}$ & $\begin{array}{l}\text { Have patient reach for cups and books on a shelf, clothes on hangers, items of } \\
\text { different size and weight on a table, and practice for } 20 \text { min several times a day } \\
\text { until performance is satisfactory }\end{array}$ \\
\hline & $\begin{array}{l}\text { Improvement in strength and } \\
\text { endurance }\end{array}$ & $\begin{array}{l}\text { Have patient exercise with elastic bands or hand weights or pedal on a recumbent } \\
\text { bicycle or walk on a treadmill while mildly short of breath }\end{array}$ \\
\hline & $\begin{array}{l}\text { Task-oriented activities relevant } \\
\text { to daily needs of patient and } \\
\text { family }\end{array}$ & $\begin{array}{l}\text { Have patient wash a car to use affected arm and challenge balance; attend } \\
\text { employment setting with patient, to help develop strategies that make possible at } \\
\text { least limited return to work }\end{array}$ \\
\hline $\begin{array}{l}\text { Beyond } 6 \text { months, } \\
\text { individual goal } \\
\text { setting }\end{array}$ & $\begin{array}{l}\text { Improvement in skills needed in } \\
\text { usual roles and out-of-home } \\
\text { activities that satisfy unmet } \\
\text { needs }\end{array}$ & $\begin{array}{l}\text { Have patient increase walking speed or distance by } 25 \% \text {; patient with aphasia } \\
\text { should read or listen to a story in a newspaper or newscast, then immediately } \\
\text { incorporate words from the story into discussion, practicing these skills at } \\
\text { varying levels of difficulty; improvement may require } 20 \mathrm{hr} \text { of training }\end{array}$ \\
\hline
\end{tabular}

